\title{
Acta
Biochimica
Polonica
}

Vol. 46 No. 1/1999

$117-123$

QUARTERLY

\section{Insulin-like growth factor I activates insulin receptor sub- strate 1 and Ras in human osteosarcoma cells}

\author{
Wlodzimierz Lopaczynski ${ }^{{ }^{\text {}} ₫}$ and Cheryl Terry \\ Endocrinology Section, Metabolism Branch, National Cancer Institute, Bethesda, Maryland \\ 20892-1374, U.S.A.
}

Received: 8 December, 1998

Key words: IGF-I receptor, tyrosine phosphorylation, IRS-1, Ras, c-Jun, MG-63

\begin{abstract}
Insulin-like growth factor I (IGF-I) stimulates multiplication of the human osteosarcoma cell line, MG-63, by acting through IGF-I receptor. We have characterized IGF-I stimulated phosphorylation of IRS-1, activation of Ras cycle and phosphorylation of c-Jun in this cell line. Serum starved MG-63 cells were (1) IGF-I stimulated and lysates were immunoprecipitated with polyclonal IRS-1 antibody or (2) metabolically labeled with $\left[{ }^{32} \mathrm{P}\right]$ orthophosphoric acid and then cells were treated with IGF-I. Cell lysates were immunoprecipitated with p21Ras antibody (Y13-259) and bound nucleotides were analysed by thin-layer chromatography. We demonstrated tyrosine phosphorylation of IRS-1/2 immunoprecipitated from MG-63 cells stimulated with IGF-I. We also showed an increased level of GTP in p21Ras immunoprecipitates from IGF-I treated cells. Nuclear extracts prepared from ${ }^{32}$ P-labeled cells before and after addition of IGF-I were immunoprecipitated with c-Jun antibody. After electrophoresis and autoradiography, phosphorylation of the cJun band was seen to be IGF-I independent. Phosphoamino acid analysis of the oJun band showed that phosphoserine was the major species.
\end{abstract}

Insulin-like growth factor I and II (IGF-I, IGF-II) action has been implicated in the pathogenesis of many different malignances, including breast and prostate cancers [1, 2]. There is a substantial evidence suggesting that insulin-like growth factor I receptor (IGF-
IR) plays a prominent role in cellular transformation, mitogenesis, and the inhibition of apoptosis [3].

The human osteosarcoma cell line, MG-63, has characteristics which make it particularly attractive for the study of growth promoting

\footnotetext{
ॠ Present address: Laboratories of Biochemistry; Department of Animal Biology, University of Pennsylvania, 3800 Spruce Street, Philadelphia, Pennsylvania 19104-6048, U.S.A.

To whom correspondence should be addressed: Endocrinology Section, Metabolism Branch, National Cancer Institute, Bethesda, Maryland 20892-1374, U.S.A., phone (301) 2639324 ; fax (301) 4969956 ; e-mail WLX@CU.NIH.GOV
} 
action of IGF-I [4]. MG-63 cells multiply in serum free medium with IGF-I as the only growth factor; in the absence of IGF-I, growth is minimal. $\left[{ }^{3} \mathrm{H}\right]$ Thymidine incorporation into DNA in MG-63 cells in response to IGF-I is almost the same as in the presence of medium containing $10 \%$ fetal calf serum (FCS). Growth stimulation by IGF-I is mediated by the IGF-I receptor since the monoclonal antibody $\alpha$ IR- 3 blocks IGF-I stimulated cell proliferation and DNA synthesis $[5,6]$.

The IGF-I receptor belongs to an expanding family of growth factor receptors the common feature of which is a tyrosine kinase domain in the cytoplasmic portion of the receptor [7]. The tyrosine kinase function of the IGF-I receptor has been shown to be vital for transmission of the growth responses to the ligand. Binding of IGF-I to the receptor leads to autophosphorylation of $\beta$-subunit of the receptor and to activation of the receptor as a tyrosine kinase [8]. Activation of the receptor tyrosine kinase by IGF-I results in phosphorylation on tyrosine residues of second messengers leading to a cascade of phosphorylations which produce the various biologic responses [9]. Several phosphoproteins have been detected following exposure of intact cells to IGF-I. One of these, insulin receptor substrate 1 (IRS-1), a member of the IRS-protein family, is a hydrophilic $131-\mathrm{kDa}$ protein, which migrates with a size between $170 \mathrm{kDa}$ and 185 $\mathrm{kDa}$ in denaturating polyacrylamide gels [10]. Tyrosine phosphorylated IRS-1 activates type I phosphatidylinositol 3'-kinase by binding to $\mathrm{SH} 2$ domains in the $85-\mathrm{kDa}$ subunit of the enzyme [11]. Thus, IRS-1 functions as an intracellular regulatory protein that transduces the IGF-IR signal by modulating the activity of certain cellular enzymes. For example, Ras signal transduction pathways link activation of IGF-I receptor tyrosine kinase to changes in gene expression. This pathway proceeds from the membrane-bound GDP/GTPbinding protein Ras, through the sequential activation of the cytoplasmic serine-threonine kinases Raf, MEK, and ERK, and leads to spe- cific gene expression in the nucleus [12]. An obvious role for the ERK signaling cascade is in regulating cell growth and differentiation. In this capacity these ERKs translocate to the nucleus after activation, where they phosphorylate/regulate a number of transcriptional factors including Elk-1 and ATF-2 [13]. Another class of MAP kinase family members, the stress activated c-Jun N-terminal kinases (JNKs), are primarily responsive to stress stimuli. JNK activation induces the phosphorylation of transcriptional factors cJun and also Elk-1, and ATF-2 [14, 15]. In contrast to the ERK pathway, Ras activation alone stimulates only a low level of JNK activity [16]. Because of cross-talk between MAP kinases, some findings suggest that IGF-I interferes with JNK activation [17].

Recently, we characterized IGF-I stimulated phosphorylation of the IGF-I receptor in the MG-63 cell line [18]. Also, we characterized the IGF-I dependent activation of ERK1 and ERK2 [19] and SHC phosphorylation (in preparation) in MG-63 cells. In the present study we investigated more molecular markers including IRS-1, Ras, and c-Jun that correlate with growth stimulation by IGF-I.

\section{MATERIALS AND METHODS}

Cell culture. MG-63 cells were obtained from American Type Culture Collection and grown to confluency in $100 \mathrm{~mm}$ tissue culture dishes in Dulbecco's minimal essential Eagle's medium supplemented with $10 \%$ fetal calf serum, $100 \mathrm{U} / \mathrm{ml}$ penicillin and $100 \mu \mathrm{g} / \mathrm{ml}$ streptomycin. Then monolayers were incubated for an additional $72 \mathrm{~h}$ in serum-free MCDB 104 (Biofluids, Inc.) to achieve growth arrest. On the day of experiment medium was removed and IGF-I $(100 \mathrm{ng} / \mathrm{ml})$ was added. After different time of the incubation as described in figure legends, cells were solubilized in 1\% Triton X-100, $20 \mathrm{mM}$ Tris/acetate, pH 7.0, 0.27 M sucrose, $1 \mathrm{mM}$ EDTA, $1 \mathrm{mM}$ EGTA, $50 \mathrm{nM} \mathrm{NaF}, 5 \mathrm{mM}$ sodium pyrophos- 
phate, $100 \mu \mathrm{M}$ sodium orthovanadate, $1 \mathrm{mM}$ sodium $\beta$-glycerophosphate, $1 \mathrm{mM}$ benzamidine, $4 \mu \mathrm{g} / \mathrm{ml}$ leupeptin, $0.1 \%(\mathrm{v} / \mathrm{v})$ mercaptoethanol. The cell lysates were preincubated with Sepharose-Protein A, and then immunoprecipitated with IRS-1 polyclonal antibody (pre-C-terminus, Upstate Biotechnology, Inc.) After immunoprecipitation, the pellet was dissolved in Laemmli SDS sample buffer [20], and samples were analysed by polyacrylamide gel electrophoresis (4-15\% minigel Bio-Rad system) and transferred to nitrocellulose $(0.45 \mu \mathrm{m})$. The blot was incubated with mono clonal phosphotyrosine antibody followed by incubation with ECL detection kit reagents.

Metabolic labeling of cells with $\Gamma^{32} \mathrm{PJH}_{3} \mathrm{PO}_{4}$ and $\mathrm{p} 21$ Ras activity determination. A previously described method [18] was used with modification. Briefly, for radiolabeling, cells were incubated in medium containing $0.1 \mathrm{mCi} / \mathrm{ml}\left[{ }^{32} \mathrm{P}\right.$ ]orthophosphoric acid $(8500-9120 \mathrm{Ci} / \mathrm{mmol})$ for $2.5 \mathrm{~h}$. After IGF-I addition the cells were immediately washed and lysed in buffer containing $50 \mathrm{mM}$ Tris/HCl (pH 8.0), $20 \mathrm{mM} \mathrm{MgCl} 2,150 \mathrm{mM}$ $\mathrm{NaCl}, 0.5 \%$ Nonidet $\mathrm{P}-40,1 \mathrm{mM}$ phenylmethylsulphonyl fluoride (PMSF) (Sigma), 20 $\mu \mathrm{g} / \mathrm{ml}$ aprotinin [18]. The lysate was used for immunoprecipitation with monoclonal Ras antibody Y13-259 (Oncogene Science). Bound nucleotides were eluted from the immunoprecipitates and analysed by ascending thin-layer chromatography (TLC) on polyethyleneiminecellulose and autoradiography.

Analysis of cJun phosphorylation. Metabolically labeled cells were also frozen in liquid nitrogen immediately after IGF-I stimulation for the analysis of c Jun phosphorylation. Frozen cells were transferred to Eppendorff tubes and solubilized in $1 \%$ Nonidet P-40, 50 $\mathrm{mM}$ Hepes ( $\mathrm{pH} 7.4$ ), $30 \mathrm{mM}$ sodium pyrophosphate, $100 \mathrm{mM}$ sodium fluoride, $5 \mathrm{mM}$ EDTA, $1 \mathrm{mM}$ sodium orthovanadate, $1 \mathrm{mM}$ PMSF and $10 \mathrm{mM}$ sodium benzoyl-L-arginine ethyl ester (BAEE) (Sigma). The cell lysates were centrifuged in a microcentrifuge at 14000 r.p.m., at $4^{\circ} \mathrm{C}$ for $30 \mathrm{~min}$. Solubilization buffer containing $2 \%$ SDS was added to each pellet, and after solubilization of the pellet the concentration of SDS was decreased to $0.1 \%$ by addition of solubilization buffer alone. To reduce nonspecific binding, samples were preincubated for $30 \mathrm{~min}$ at $4^{\circ} \mathrm{C}$ with Pansorbin (Calbiochem), at dilution 1:30. Pansorbin was then removed by centrifugation. Supernatants were incubated overnight at $4^{\circ} \mathrm{C}$ with $10 \mu \mathrm{g} / \mathrm{ml}$ of polyclonal c-Jun/AP-1 antibody (Oncogene Science). Then Pansorbin was added (1:30 dilution). Immune complexes were washed four times with solubilization buffer and dissociated by boiling for $3 \mathrm{~min}$ in Laemmli sample buffer. The samples were electrophoresed on a $10 \%$ polyacrylamide gel.

For phosphoamino acid analysis, immunoprecipitated ${ }^{32} \mathrm{P}$-labeled cJun was eluted from gel slices, digested with trypsin, subjected to acid hydrolysis in $6 \mathrm{M} \mathrm{HCl}$ at $110^{\circ} \mathrm{C}$ for $1 \mathrm{~h}$, and phosphoamino acids were separated by thin-layer electrophoresis [22].

\section{RESULTS}

It was possible to demonstrate tyrosine phosphorylation of IRS-1 immunoprecipitated from MG-63 cells stimulated by IGF-I. Figure 1 shows immunoblots probed with phosphotyrosine antibody which indicated that IRS-1 (approx. $180 \mathrm{kDa}$ ) and probably coimmunoprecipitated IRS-2 (approx. $190 \mathrm{kDa}$ ) were tyrosine phosphorylated after $30 \mathrm{~s}$ stimulation by IGF-I. The level of phosphotyrosine increased after $1 \mathrm{~min}$ and stayed unchanged for another $4 \mathrm{~min}$. This experiment shows that IRS-1 is rapidly phosphorylated after IGF-I stimulation in MG-63 cells.

The process of IGF-I-induced p21Ras-GTP formation involves the binding Grb2 to tyrosine phosphorylated IRS-1 and/or She protein. To determine that Ras is activated after addition of IGF-I to MG-63 cells p21Ras was immunoprecipitated from ${ }^{32} \mathrm{P}$-labeled cell lysates, and the guanine nucleotide status was determined by thin-layer chromatogra- 


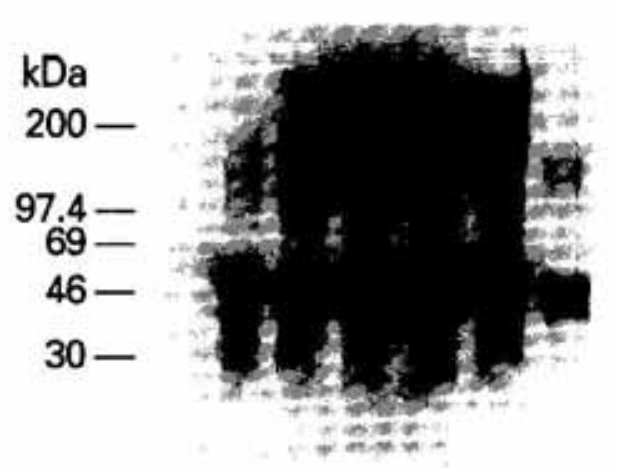

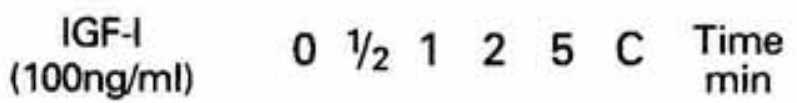

Figure 1. Tyrosine phosphorylation of IRS-1 in MG-63 cells stimulated with IGF-I.

Cells were incubated in absence or presence of IGF-I (for 1/2, 1, 2, and $5 \mathrm{~min}$ ) and then were lysed and immunoprecipitated with polyclonal IRS-1 antibody. Immunoprecipitates were resolved by SDS/PAGE (4-15\% gradient mini-gel), transferred to nitrocellulose, and immunoblotted with monoclonal tyrosine antibody. Migration of IRS-1 (180 kDa) and probably IRS-2 (190 kDa) according to molecular standards are indicated. The last control lane (C) shows the results of immunoprecipitation without MG-63 cell lysate.

phy, followed by autoradiography (Fig. 2). An autoradiogram of a chromatogram shows increase of p21Ras-GTP level induced by IGF-I in MG-63 cells.

To investigate whether c-Jun underwent phosphorylation following addition of IGF-I to MG-63 cells, we labeled cells with $\left[{ }^{32} \mathrm{P}\right]$ orthophosphoric acid and analysed the nuclear extracts using immunoprecipitation with cJun antibody. After electrophoresis and autoradiography, we observed that cJun is highly phosphorylated in unstimulated cells (Fig. 3A). Addition of IGF-I for a different times to the MG-63 cells does not change the phosphorylation level of cJun. Phosphoamino acid analysis of the c-Jun at "zero" time suggests that cJun under basal conditions is heavily phosphorylated on serine residues and it is unchanged during stimulation with IGF-I (Fig. 3B).

\section{DISCUSSION}

A goal in the study of the IGF-IR signal transduction is to identify the patterns of subcellular pathways that are activated by IGFs. IRS-1 and p21Ras are implicated in signaling for IGF-I and insulin and some other growth factors and cytokines as well. After discovery of the first MAP kinase signaling pathway the ERKs were identified as elements downstream of Ras capable to regulate cell growth and differentiation [23]. In this capacity, ERKs translocate to the nucleus after activation, where they phosphorylate and regulate a number of transcription factors including Elk-1 [13]. Previously, we observed increasing amount of activated (phosphorylated) ERKs in MG-63 cell lysates and nuclear extracts af-

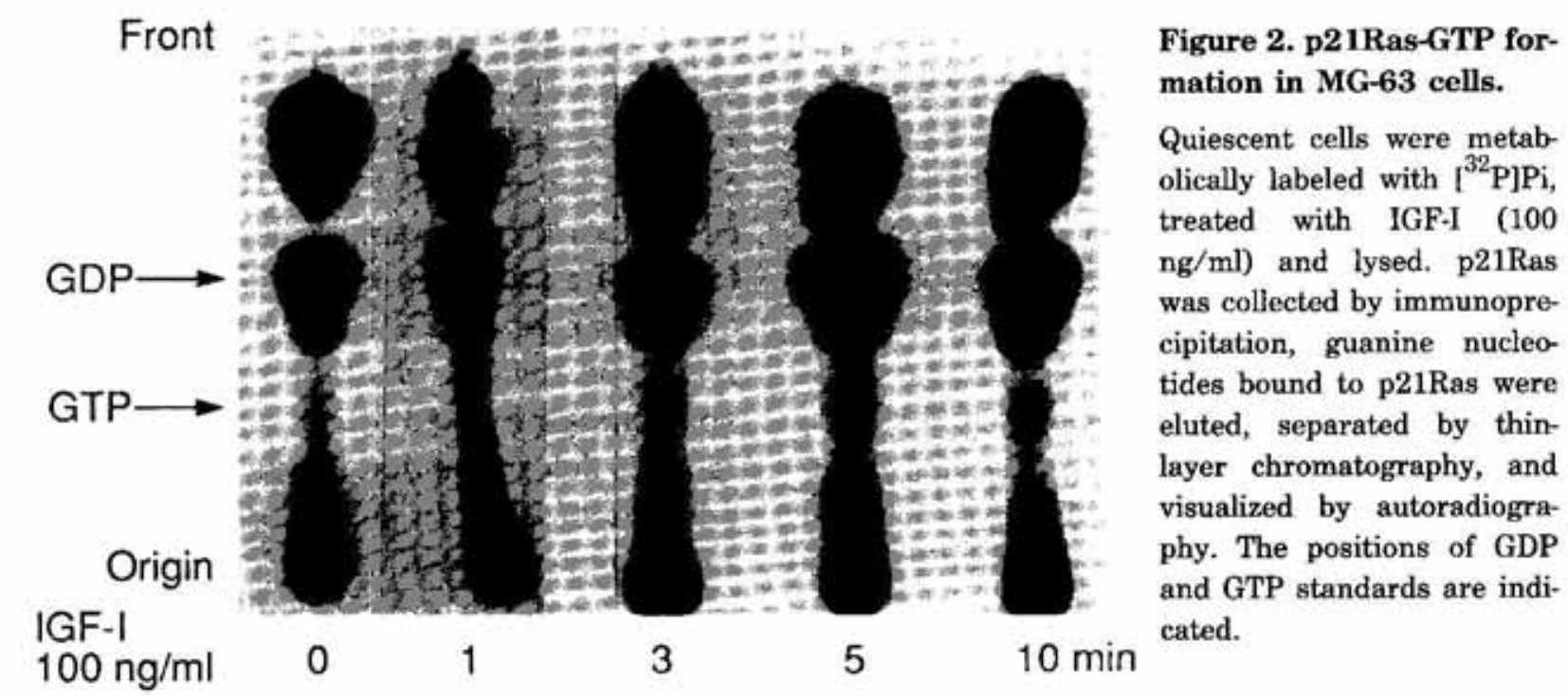




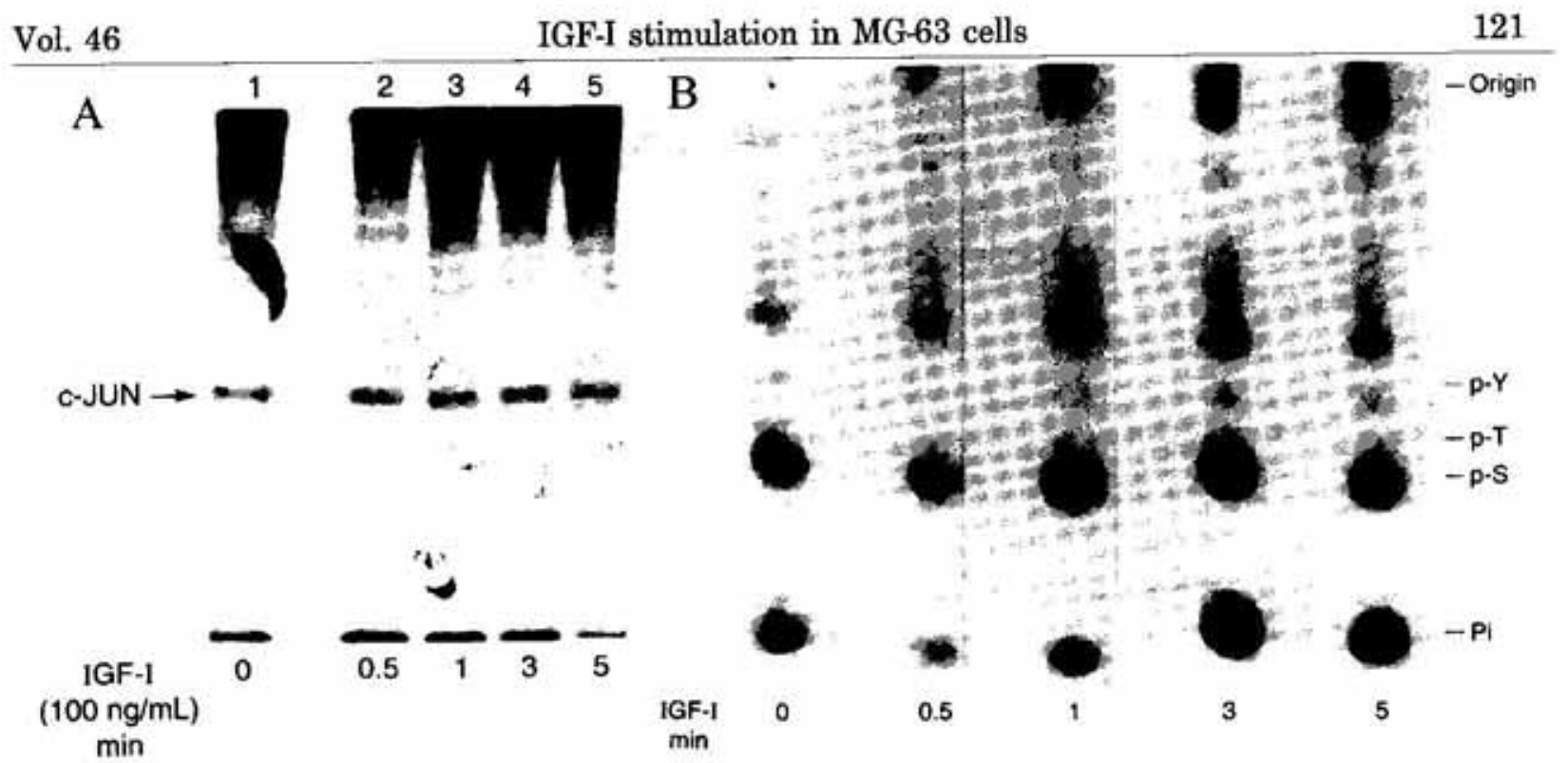

Figure 3. c-Jun Phosphorylation in MG-63 cells after addition of IGF-I.

Serum-starved MG-63 cells were labeled with $\left[{ }^{32}\right.$ PJorthophosphoric acid and stimulated with IGF-I as described in Methods and the legend of Fig. 2. Nuclear extracts were immunoprecipitated by cJun polyclonal antibody using Pansorbin. Panel A, immune complexes were analysed by SDS/PAGE (10\% gel) and autoradiography. Panel B, gel slices containing cJun (Panel A) were treated with trypsin, acid hydrolyzed and phosphoamino acid analysed by thin-layer electrophoresis. The cathode is at the top of the figure, $\mathrm{Pi}-\left[{ }^{32} \mathrm{P}\right]$ phosphate, $\mathrm{p}-\mathrm{S}=$ phosphoserine, $\mathrm{p}-\mathrm{T}=$ phosphothreonine, $\mathrm{p}-\mathrm{Y}$ - phosphotyrosine.

ter incubation with IGF-I. This was demonstrated by phosphotyrosine antibody Western blotting which showed the appearance in the nucleus of tyrosine phosphorylated 44/46 kDa bands which were IGF-I dependent [22].

In the present study we demonstrated the tyrosine phosphorylation of IRS-1 in the IGF-I receptor signaling pathway in MG-63 cells. IGF-I rapidly stimulated IRS-1 (and probably IRS-2) tyrosine phosphorylation at a physiological dose $(100 \mathrm{ng} / \mathrm{ml})$ in MG-63 cells. Furthermore, IGF-I treatment increased the p21Ras-GTP level. IRS-1 contains 21 potential tyrosine phosphorylation sites, but only 8 were identified as a phosphorylated by the insulin receptor [24]. The phosphorylation sites in IRS-1 serve a dual function by linking the IGF-I receptor to downstream signaling element such as Ras, and ERKs. Firstly, IRS-1 is a substrate for the IGF-I receptor after binding to phosphotyrosine 950 on the $\beta$ subunit [25]. Secondly, the phosphorylated IRS-1 binds specifically to proteins containing SH2 domains transmitting the signal through for example Ras to the nucleus. Therefore, we conclude that phosphorylated IRS-1 and p21Ras-GTP might be a good molecular markers of IGF-I response in MG-63 cells.

Pulverer and collegues [26] provided evidence that MAP kinases specifically phosphorylate cJun and that phosphorylation positively regulates the activity of c-Jun as a transcription factor. Moreover, Oemar et al. [27] observed increased phosphotyrosine level in c-Jun after IGF-I stimulation in kidney mesangial cells derived from genetically diabetic mice $(\mathrm{db} / \mathrm{db})$ as well as in the epidermoid carcinoma cell line CaSki. These results suggest that the mechanism(s) responsible for cJun activation may involve different signaling pathways, which has been reported by others to involve JNK-stress regulated kinase [13, 17]. Therefore, we asked whether c-Jun is phosphorylated following treatment of MG-63 cells by IGF-I. However, we found that c-Jun was phosphorylated on serine in unstimulated cells, and we did not detect IGF-I dependent tyrosine phosphorylation of cJun in MG-63 cells. The mechanism for this divergence is not understood, but may involve cell 
type-specific inhibition or simply lack of specific phosphatases or cellular kinases in osteosarcoma cells which are involved in the tyrosine and/or threonine phosphorylation of cJun in normal cells.

Overall, the results presented here implicate IRS-1/2 and p21Ras as signal transducing molecules for IGF-I, possibly functioning as a part of a kinase cascade linking growth factor receptors to mitogenesis and other cell responses in human osteosarcoma cells. Observation of the presence of the constitutively serine-phosphorylated c-Jun in the nucleus in MG-63 cells is a topic for further investigation in order to understand the signaling pathways in neoplastic cells.

\section{RE F E R E N C E S}

1. Chan, J.M., Stampfer, M.J., Giovannucci, E., Gann, P.H., Ma, J., Wilkinson, P., Honnekens, C.H. \& Pollack, M. (1998) Plasma insulin-like growth factor-I and prostate cancer risk: A prospective study. Science, 279, 563-566.

2. Hankinson, S.E., Willett, W.C., Colditz, G.A., Hunter, D.J., Michaud, D.S., Deroo, B., Rosner, B., Speizel, F.E. \& Pollack, M. (1998) Circulating concentrations of insulin-like growth factor-I and risk of breast cancer. Lancet 351, 1393-1396.

3. Werner, H. \& LeRoith, D. (1997) The insulinlike growth factor-I receptor signaling path. ways are important for tumorgenesis and inhibition of apoptosis. Crit. Rev. Oncogen. 8, 71-92.

4. Furlanetto, R.W., Harwell, S.E. \& Frick, K.K. (1994) Insulin-like growth factor-I induces cyclin-D1 expression in MG63 human osteosarcoma cells in vitro. Mol. Endocrinol. 8, 510-517.

5. Furlanetto, R.W. (1988) Receptor-mediated endocytosis and lysosomal processing of insulin-like growth factor I by mitogenically responsive cells. Endocrinology 122, 20442053.

6. Pollak, M.N., Polychronakos, C. \& Richard, M. (1990) Insulin-like growth factor I: A potent mitogen for osteogenic sarcoma. J. Natl. Cancer Inst. 82, 301-305.

7. Yarden, Y. \& Ullich, A. (1988) Growth factor receptor tyrosine kinases. Annu. Rev. Biochem. 57, 443-478.

8. Nissley, P.S., \& Lopaczynski, W. (1991) Insulin-like growth factor receptors. Growth Factors 5, 29-43.

9. Nissley, P. \& Lopaczynski, W. (1993) Insulinlike growth factor receptors and signaling mechanisms; in Growth Hormone and Somatomedins during Lifespan (Muller, E.E., Cocchi, D. \& Locatelli, V., eds.) pp. 72-81, SpringerVerlag, Stuttgart.

10.Sun, X.J., Rothenberg, P., Kahn, C.R., Backer, J.M., Araki, E., Wilden, P.A., Cahill, D.A., Goldstein, B.J. \& White, M.F. (1991) The structure of the insulin receptor substrate IRS-1 defines a unique signal transduction protein. Nature 352, 73-77.

11.Myers, M.G., Backer, J.M., Sun, X.J., Shoelson, S., Hu, P., Schlessinger, J., Yoakim, M., Schaffhausen, B. \& White, M.F. (1992) IRS-1 activates the phosphatidylinositol $3^{\prime}$-kinase by associating with src homology 2 domains of p85. Proc. Natl. Acad. Sci. U.S.A. 89, 1035010354.

12.Pawson, T. \& Scott, J.D. (1997) Signaling through scaffold, ancoring, and adaptor proteins. Science 278, 2075-2080.

13. Karin, M. (1995) The regulation of AP-1 activity by mitogen-activated protein kinases. $J$. Biol. Chem. 270, 16483-16486.

14. Gupta, S., Campbell, D., Derijard, B. \& Davies, R.J. (1995) Transcription factor ATF2 regulation by the JNK signal transduction. Science 267, 389-393. 
15. Woodgett, J.R., Avruch, J. \& Kyriakis, J.M. (1995) Regulation of nuclear transcription factors by stress signals. Clin. Exp. Pharmacol. Physiol. 22, 281-283.

16.Jessel, T.M. \& Goodman, C.S. (1996) Development: neural development: are there any surprises left? Curr. Opin. Neurobiol. 6, 1-2.

17. Cheng, H.-L. \& Feldman, E.L. (1998) Bidirectional regulation of $\mathrm{p} 38$ kinase and $\mathrm{cJun} N$ terminal protein kinase by insulin-like growth factor-I. J. Biol. Chem. 273, 14560-14565.

18. Lopaczynski, W., Harris, S. \& Nissley, P. (1993) Insulin-like growth factor-I (IGF-I) dependent phosphorylation of the IGF-I receptor in MG-63 cells. Regulatory Peptides 48, 207216.

19. Lopaczynski, W., Harris, S. \& Nissley, P. (1999) Activation of extracellular signalregulated kinases ERK1 and ERK2 by insulinlike growth factor I in MG-63 cells. Horm. Metab. Res. (in press).

20.Laemmli, U.K. (1970) Cleavage of structural proteins during the assembly of the head of bacteriophage T4. Nature 227, 680-685.

21. Yonezawa, K., Ando, A., Kaburagi, Y., Yamamoto-Honda, R., Kitamura, T., Hara, K., Nakafuku, M., Okabayashi, Y., Kadowaki, T., Kaziro, Y. \& Kasuga, M. (1994) Signal transduction pathways from insulin receptors to
Ras. Analysis by mutant insulin receptors. $J$. Biol. Chem. 269, 4634-4640.

22. Hunter, T. \& Sefton, B.M. (1980) Transforming gene product of Rous sarcoma virus phosphorylates tyrosine. Proc. Natl. Acad. Sci. U.S.A. 77, 1311-1315.

23. Neary, J.T. (1997) MAPK cascades in cell growth and death. News Physiol. Sci. 12, 286-293.

24.Sun, X.J., Crimmins, D.L., Myers, M.G., Miralpeix, M. \& White, M.F. (1993) Pleiotropic insulin signals are engaged by multisite phosphorylation of IRS-1. Mol. Cell. Biol. 13, 7418-7428.

25. Dey, B., Frick, K., Lopaczynski, W., Nissley, S.P. \& Furnaletto, R. (1996) Evidence for direct interaction of the IGF-I receptor with IRS-1, She, and Grb-10. Mol. Endocrinol. 10, 631-641.

26. Pulverer, B.J., Kyriakis, J.M., Avruch, J., Nikolakaki, E. \& Woodgett, J.R. (1991) Phosphorylation of c-jun by MAP kinases. Nature 353, 670-674.

27. Oemar, B.S., Law, N.M. \& Rosenzweig, S.A. (1991) Insulin-like growth factor-1 induces tyrosyl phosphorylation of nuclear proteins. $J$. Biol. Chem. 266, 24241-24244. 